\title{
What do pupils of Surgut schools know and what skills do they have in terms of BLS modern algorithms
}

\author{
Authors: Oleg Malkov ${ }^{1}$ Alena Govorukhina ${ }^{1}$ Anna Novoselova ${ }^{1}$ Ilya Malkov² (presenter) \\ 1-Surgut State Pedagogical University 2-MB educational institution lyceum
}

Relevance of the research:

\section{Out-of-hospital cardiac arrests (per year): Russia 350000 \\ Surgut $\sim 200$ \\ Europe $\sim 350000^{1-2}$}

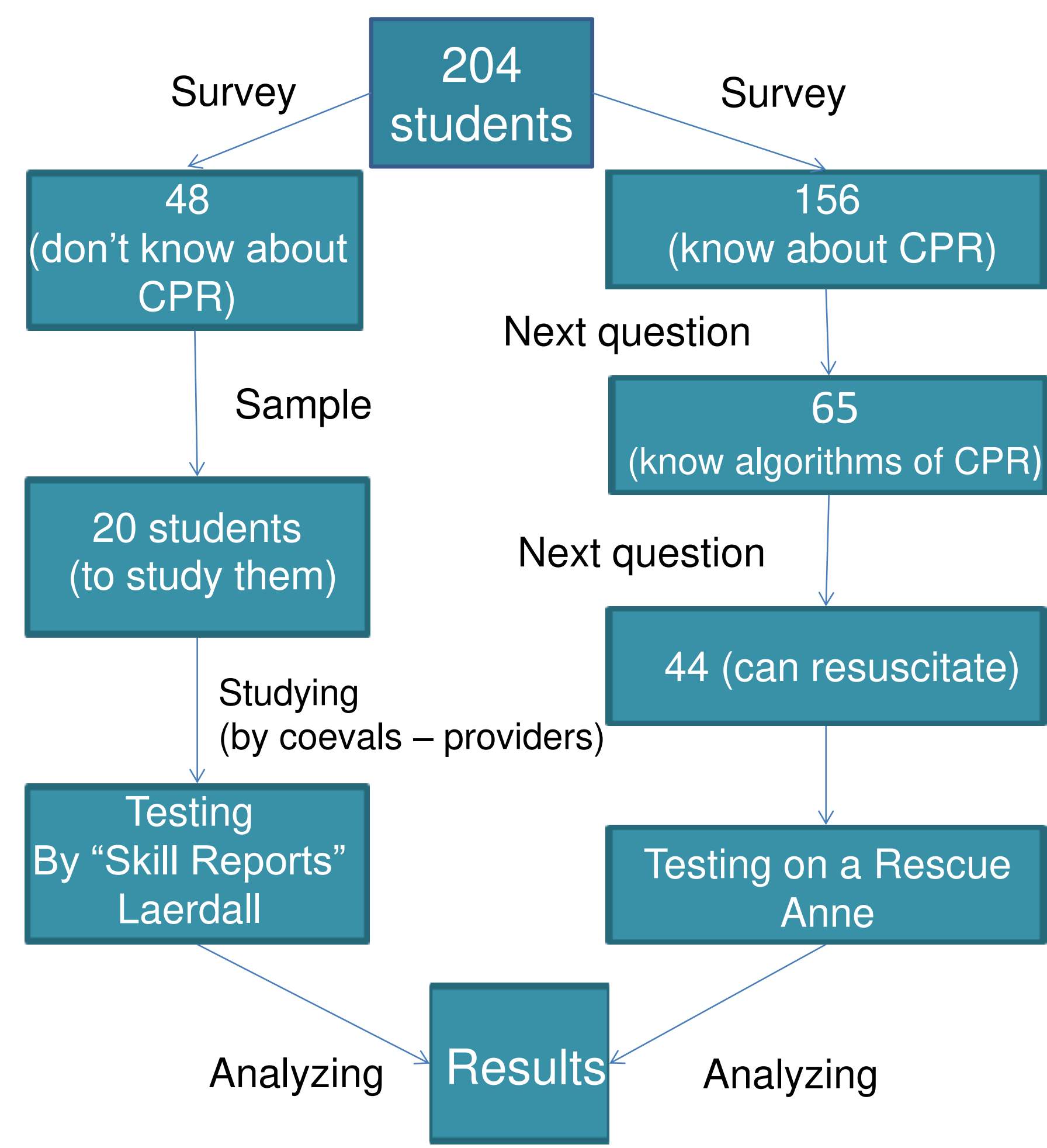

\section{Results of the study}

By results of questioning of $76,5 \%(n=156)$ high school students know about BLS. From them 41,7\% ( $n=65)$ have specified in knowledge of modern algorithm of BLS. It is $31,9 \%$ of all students. Ability to make BLS has noted in the questionnaires of $21,6 \%(n=44)$ respondents. The check of practical skills at group of students $(n=44)$, who specified ability presence to make BLS, on a dummy under last ERC recommendations has shown that nobody of students had that skill. The master class that was made at last stage, supervised by studied peers on BLS under recommendations ERC 2015 has allowed to generate modern representation at high school students on algorithm

\author{
Survival after cardiac arrest: \\ $1 / 10$ of victims (Russia) \\ Russia 35000 \\ Surgut $\sim 20$
}

\section{Purpose of the study}

To increase the level of competence among high school students in Surgut on modern BLS algorithms.

\section{Materials and methods}

204 high school students have been involved in research at the age of $16-17$ years. At the first investigation phase, we had a public opinion poll for high school students about their knowledge and abilities on BLS. Then we chose those $(n=44)$ who have answered that they can make BLS. We checked the practical skills of using BLS on a dummy on a procedure of providers ERC (2015). At a following stage this group had the master class on modern algorithms BLS (ERC, 2015) that was made by studied peers.

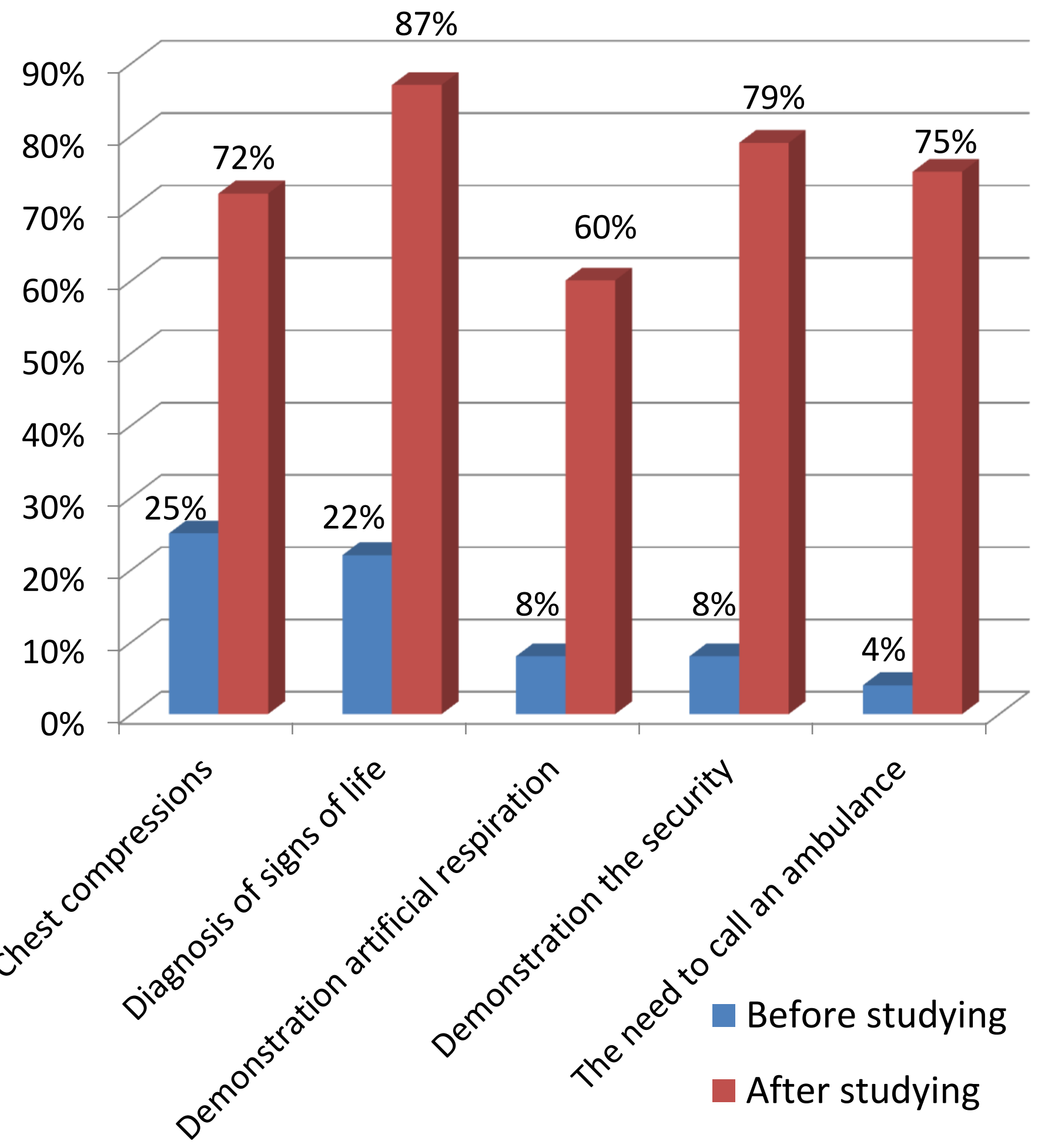
BLS taking into last recommendations (ERC).

The conclusion

The result of this research has shown extremely low level of competence of schoolboys of a Surgut city on modern BLS algorithms. Popularization by studied peers and practice using of modern methods form needed level of competence of the students.

Sources:

1) Hasselqvist-Ax., I., Early cardiopulmonary resuscitation in out-of-hospital cardiac arrest. 2015

2) Wissenberg, M. Association of national initiatives to improve cardiac arrest management with rates of bystander intervention and patient survival after out-of-hospital cardiac arrest. 2013

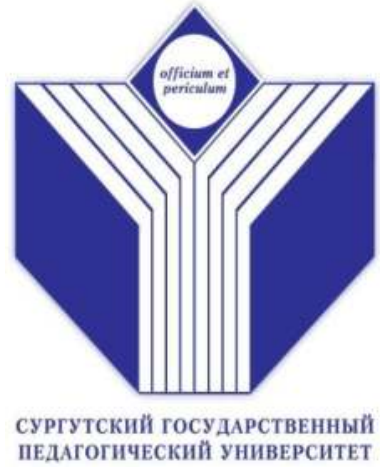

